\title{
Cephalometric Hard and Soft Tissue Norms for Sudanese Adults
}

\author{
Dr Eman I Salama,' Dr Amal H Abuaffan² \\ 'Lecturer, ${ }^{2}$ Associate Professor, Department of Orthodontics, \\ Faculty of Dentistry, University of Khartoum, Sudan
}

Correspondence: Dr Amal H Abuaffan; Email: amalabuaffan@yahoo.com

\section{ABSTRACT}

Introduction: Cephalometric norms of various populations show differences between diverse ethnic and racial groups. Thus, numbers of cephalometric norms have been established for different ethnic groups.

Objective: To assess skeletal, dental and soft tissue features in a sample of well-balanced face of Sudanese university students.

Materials \& method: Lateral cephalographs were taken from 18-25 years old 35 male and 38 female Sudanese university students with balanced facial profile and Class I occlusion with no previous orthodontic treatment. Fourteen angular and five linear measurements, and facial index were recorded according to Husund analysis. Male and female mean values were compared statistically using Student t-test.

Result: Statistically significant differences were noted between both genders especially in skeletal variables $\mathrm{SNA}^{\circ}, \mathrm{SNB}^{\circ}, \mathrm{SNPg}^{\circ}$, ML- NSL', NL-NSL', UFH, LFH and dental variable I -I. Holdaway angle showed no significant difference between the genders. Skeletally, maxilla and mandible of the Sudanese sample were more prognathic compared to Caucasians and Arabs but less prognathic than the Africans. Dentally, maxillary and mandibular incisors were more proclined compared to Arabs and Caucasians. Soft tissue analysis showed more lip protrusion in Sudanese adults.

Conclusion: The study offered normative cephalometric standards for Sudanese adults, which were specific for each gender group. The normative values showed that the Sudanese sample lied between African and Arab values which might suggest that the studied sample had an Afro-Arabian mixture.

Keywords: bimaxillary protrusion, cephalometric norms, Sudanese

\section{INTRODUCTION}

In the beginning of the twentieth century, Paccini in Italy realized the implications of cephalometric radiography, however the standardized method of taking cephalometric radiograph was later developed by Broadbent in United States. ${ }^{2}$ The cephalometric evaluation of skeletal, dental and soft tissue morphologies is considered one of the most significant tools in orthodontic diagnosis and treatment planning. ${ }^{3}$ Cephalometric norms has been used to determine the severity and location of dentofacial discrepancies and to evaluate the orthodontic treatment changes. ${ }^{4}$

Since the development of cephalometric radiography, diverse methods of analyses developed by Downs, Steiner, Hasund, McNamara and many others ${ }^{5-9}$ have been used to identify the dental and facial structures of different ethnic groups. Different cephalometric values has been reported by several authors showing the wide range of variety in cephalometric norms among different ethnic groups and gender. ${ }^{4,10-26}$ Saudis have been shown to have features of more facial convexity than the Caucasians with fuller lips than the Whites. ${ }^{12}$ Another investigation demonstrated no differences between Saudi males and females except that the males showed straighter profiles than females. ${ }^{13}$ Jordanians had a reduced lower face height and proclined upper and lower incisors in comparison with the British sample. ${ }^{14}$ According to a study, Emiratis had no gender dimorphism except SNpalatal plane, which was in the female sample with more bimaxillary protrusion when compared to Caucasians. ${ }^{15}$ In another study, Emirates' males showed greater facial height and longer mandibular length than females. ${ }^{16}$

Egyptians $^{4,17}$ and Nubians ${ }^{18}$ also showed bimaxillary features and acute interincisal angle which distinguished them from Caucasians with some gender dimorphism. Nigerian and Kenyan were found to have a low value 


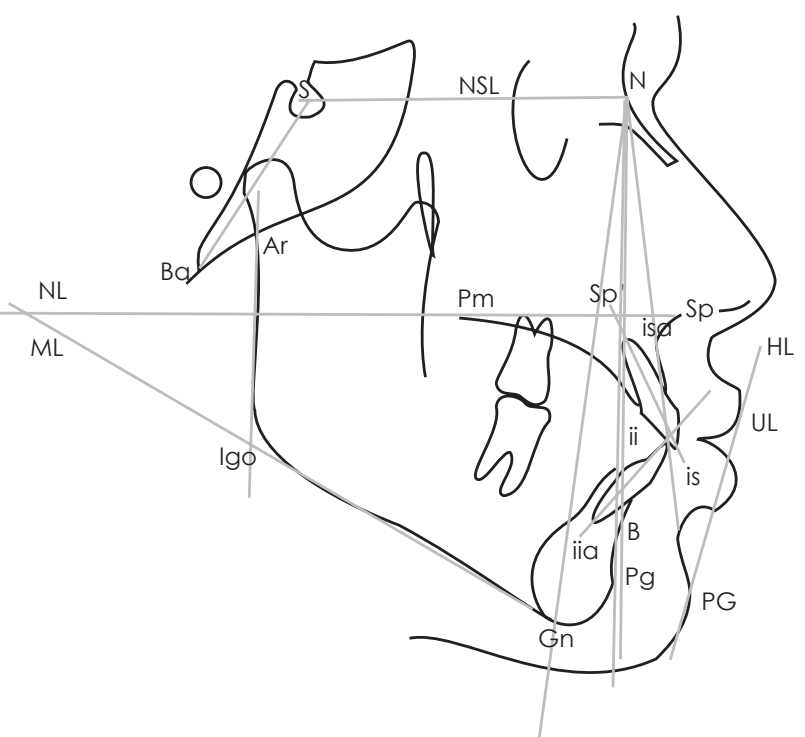

Figure 1. Cephalometric hard and soft tissue reference lines. Nasion-sella line-NSL, nasal line-NL, mandibular line-ML, Nasion point-A line -NAL, Nasion point-B line -NBL, Upper incisor edge to upper incisor apex - I, Lower incisor edge to lower incisor apex - İ, Holdaway line (PG-UL) -HL

of interincisal angle with a typical feature of bimaxillary protrusion. ${ }^{19-22}$ Zimbabweans were found to have a greater ANB angle and lower interincisal angle. ${ }^{23}$ The Japanese population have also been investigated extensively.24-26 When compared with Caucasians, they had larger antero-posterior facial dimensions, lower vertical facial dimensions with straighter bilabial inclination. ${ }^{24}$

The purpose of this study was to establish cephalometric norms among a Sudanese adult sample.

\section{MATERIALS AND METHOD}

Five hundred and ninety Sudanese dental students were examined in the university orthodontic clinic. Out of which, 96 fulfilled the criteria of selection, however, many refused to participate in the study and were excluded. Thus lateral cephalometric radiographs were obtained from 73 Sudanese adults including 35 males and 38 females aged between 18-25 years. The study was conducted after obtaining ethical approval was from the University Research Committee and consent from the participants.

All subjects were selected among the dental students on the basis of:

- Sudanese nationality with up to great grandparents born in Sudan

- Balanced facial profile with competent lips

- Without any obvious asymmetry and craniofacial deformities

- Full permanent dentition (except for the third molars)

- Class I molar, incisor and canine relationship
- Normal overjet and overbite

- Normal transversal occlusion

- Aligned or mildly crowded teeth (up to $2 \mathrm{~mm}$ )

- $\quad$ No previous orthodontic treatment

All cephalometric radiographs were taken with the teeth in centric occlusion and lips in repose. Each subject's head was kept in the natural head position by looking at own eyes in a mirror placed two meters away. The radiographs were exposed at $73 \mathrm{KV}, 10 \mathrm{~mA}$ for 1.2 seconds. The right side of the patient was facing the cassette. A $150 \mathrm{~cm}$ tube target distance to the midsagittal plane was used with $20 \mathrm{~cm}$ midsagittal plane to the film distance resulting in $13 \%$ enlargement. Cephalograph tracings were done manually on 0.003 matte acetate cephalometric tracing papers using $0.5 \mathrm{~mm}$ lead pencil. Fourteen angular, five linear measurements and facial index (Figure 1) according to Hasund analysis ${ }^{7}$ (Table 1) were recorded and analyzed.

Descriptive statistics were computed for each cephalometric variable using the SPSS program. Comparison was made between male and female values using independent sample student t-test. The level of significance was set at $5 \%(<0.05)$ level.

Fifteen cephalographs were retraced after four weeks interval by the same operator to determine the error of the method. Dahlberg's formula and paired t-test were used to estimate the error of the method. ${ }^{27}$

\section{RESULT}

The mean and standard deviation of fourteen angular, five linear measurements and a facial index for Sudanese male and female samples according to Hasund analysis are presented in Table 2. The mean age of the subjects examined was $22.5+3$ years with no significant difference between male and female samples.

Antero-posteriorly, males were found to have more prognathic maxilla and mandible than females as indicated by the significant increase in $\mathrm{SNA}^{\circ}, \mathrm{SNB}^{\circ}$ and $\mathrm{SNPg}^{\circ}$ angles. Regarding the vertical inclination, females showed significant increase in maxillary and mandibular inclinations to the base of the skull compared to males. Table 2 reveals that males had increased upper and lower facial heights than the females $(p<0.01)$.

Although there was no significant difference in the upper and lower incisors to the maxillary and mandibular bases respectively; the females showed significant decrease in inter-incisal angle indicating greater bimaxillary proclination of the incisors in females compared to males $(p<0.05)$. 
Table 1: Angular and linear parameters used in the study

\begin{tabular}{|c|c|c|}
\hline \multicolumn{3}{|l|}{ Skeletal variables } \\
\hline \multirow{5}{*}{ Antero-posterior } & $\mathrm{SNA}^{\circ}$ & Sella-nasion-point A, representing maxillary protrusion in relation to anterior cranial base \\
\hline & $\mathrm{SNB}^{\circ}$ & Sella-nasion-point B, representing the mandibular protrusion in relation to anterior cranial base \\
\hline & $\mathrm{ANB}^{\circ}$ & to the anterior cranial base \\
\hline & $\mathrm{SNPg}^{\circ}$ & Sella-nasion-pogonion, representing the anterior-posterior position of the chin to anterior cranial base \\
\hline & $\mathrm{NSBa}^{\circ}$ & Nasion- Sella -Basion, representing the Sagittal relation of the clivus to the anterior base of the skull \\
\hline \multirow{4}{*}{$\begin{array}{l}\text { Vertical } \\
\text { inclination }\end{array}$} & ML-NSL ${ }^{\circ}$ & Mandibular plane angle relative to anterior cranial base \\
\hline & NL-NSL ${ }^{\circ}$ & Maxillary plane angle relative to anterior cranial base \\
\hline & ML-NL ${ }^{\circ}$ & Maxillary-mandibular plane angle \\
\hline & Gn-tgo-Ar ${ }^{\circ}$ & Gnathion-tangent gonion-articulare, representing the vertical form of mandible relating body and ramus \\
\hline \multirow{3}{*}{ Face height } & N-Sp' mm & Upper facial height \\
\hline & Sp'-Gn mm & Lower facial height \\
\hline & $\frac{\mathrm{N}-S p^{\prime}}{S p^{\prime}-G n} \times 100$ & Relationship between upper and lower partial facial heights of the total anterior facial height \\
\hline \multirow{2}{*}{ Chin prominence } & Pg-NB mm & Pogonion-NB line, representing the size of the bony chin prominence \\
\hline & $\mathrm{N}^{\circ}$ & Nordeval angle, representing the prominence of the bony chin in relation to mandibular plane-ML \\
\hline \multicolumn{3}{|l|}{ Dental variables } \\
\hline \multicolumn{2}{|l|}{$1-\bar{I}^{\circ}$} & Inter-incisal angle, representing the position of the upper and lower incisors \\
\hline \multicolumn{2}{|l|}{${\mathrm{I}-N A^{\circ}}^{\circ}$} & Upper incisor inclination relative to NA line \\
\hline \multicolumn{2}{|l|}{$\mathrm{I}^{\circ}-\mathrm{NB}^{\circ}$} & Lower incisor inclination relative to NB line \\
\hline \multicolumn{2}{|l|}{ I-NA mm } & Representing the horizontal position of upper incisor \\
\hline \multicolumn{2}{|l|}{ I -NB mm } & Representing the horizontal position of lower incisors \\
\hline \multicolumn{3}{|c|}{ Soft tissue variable } \\
\hline \multicolumn{2}{|l|}{$H^{\circ}(\mathrm{UL}-\mathrm{PG}: \mathrm{NB})$} & Holdaway angle, relating soft tissue profile to hard tissue profile \\
\hline
\end{tabular}

\section{DISCUSSION}

Cephalometric studies on non-caucasian subjects indicate that there are measurable skeletal and dental differences when compared to Caucasians. ${ }^{28}$ The present study was conducted in the University due to its racial heterogeneity of the enrolled students. The inclusion criteria and methodology were used to identify normative values that can assist in diagnosis and treatment planning for Sudanese adults seeking orthodontic treatment. The data were divided according to gender in order to obtain more specific and useful cephalometric normative values. The cephalometric values from the present Sudanese study were compared to published data of Arab and African populations (Table 3).

The highest error in the measurement (0.26) undertaken in the current study was in determining the angle of the cranial base flexure measurement (NSBa). It could be attributed to the difficulty of locating Basion point as it is one of the most difficult points to identify in lateral cephalograph. ${ }^{28}$

The present study revealed that there was gender dimorphism for SNA, SNB, SNPg angles $(p<0.01)$ with the males having greater values. Similar ANB angle measurement was demonstrated among the samples when compared to Arabs: ${ }^{11-17}$ but lower value were obtained when compared to Africans..$^{18-22}$ The mean values of maxilla and mandible to cranial base in the current study were larger than those of Saudi' ${ }^{12}$ Jordanians $^{14}$ and Emirati ${ }^{15}$ but lesser than those of the Zimbabweans. ${ }^{23}$

The present study exhibited no statistical difference between males and females regarding the ML-NL; although males showed more anteriorly inclined maxillae and mandibles (NL-NSL and ML-NSL) than females $(p<0.01)$. The average ML-NL angle in the present study showed higher values than those of the Zimbabwean population ${ }^{23}$ indicating a steeper mandible, while it was less compared to the Jordanians ${ }^{14}$ and Emiratis populations. ${ }^{15}$

The present study revealed that there was significant gender difference in upper and lower anterior facial heights. Males had increased upper and lower anterior facial height than the females $(p<0.01)$. The mean value for the upper and lower anterior facial height of the present investigation for both genders was found to be similar to the Egyptian sample. ${ }^{4}$ The present study males showed more prominent chin in males than females though not statistically significant. 
Table 2: Dentofacial pattern of Sudanese adults with comparison between male and female subjects

\begin{tabular}{|c|c|c|c|c|c|c|c|c|}
\hline \multirow{2}{*}{\multicolumn{2}{|c|}{ Variable }} & \multicolumn{2}{|c|}{ Total $(n=73)$} & \multicolumn{2}{|c|}{ Male $(n=35)$} & \multicolumn{2}{|c|}{ Female $(n=38)$} & \multirow{2}{*}{$p$-Value } \\
\hline & & Mean & SD & Mean & SD & Mean & SD & \\
\hline \multicolumn{9}{|c|}{ Skeletal variables } \\
\hline \multirow{5}{*}{ Antero-posterior } & SNA $^{\circ}$ & 84.54 & 2.07 & 85.57 & 1.66 & 83.59 & 1.96 & $<0.01^{* *}$ \\
\hline & $\mathrm{SNB}^{\circ}$ & 81.51 & 2.15 & 82.50 & 1.89 & 80.59 & 1.98 & $<0.01^{* *}$ \\
\hline & $\mathrm{ANB}^{\circ}$ & 3.03 & 1.43 & 3.07 & 1.39 & 3 & 1.48 & NS \\
\hline & $\mathrm{SNPg}^{\circ}$ & 82.22 & 2.46 & 83.30 & 2.28 & 81.22 & 2.2 & $<0.01^{* *}$ \\
\hline & $\mathrm{NSBa}^{\circ}$ & 135.97 & 5.48 & 135.21 & 4.59 & 136.66 & 6.18 & NS \\
\hline \multirow{4}{*}{$\begin{array}{l}\text { Vertical } \\
\text { inclination }\end{array}$} & ML-NSL ${ }^{\circ}$ & 31.25 & 5.63 & 29.41 & 5.57 & 32.93 & 5.2 & $<0.01^{* *}$ \\
\hline & NL-NSL ${ }^{\circ}$ & 8.61 & 3.77 & 7.19 & 3.17 & 9.92 & 3.83 & $<0.01^{* *}$ \\
\hline & ML-NL ${ }^{\circ}$ & 22.82 & 4.84 & 22.51 & 5.16 & 23.09 & 4.58 & NS \\
\hline & Gn-tgo-Ar ${ }^{\circ}$ & 117.85 & 6.75 & 116.71 & 6.3 & 118.89 & 7.05 & NS \\
\hline \multirow{3}{*}{ Face height } & N-Sp' mm & 55.63 & 3.89 & 57.06 & 4.09 & 54.32 & 3.22 & $<0.01^{* *}$ \\
\hline & Sp'-Gn mm & 73.29 & 5.93 & 76.26 & 5.77 & 70.55 & 4.67 & $<0.01^{* *}$ \\
\hline & $\frac{\mathrm{N}-S p^{\prime}}{S p^{\prime}-G n} \times 100$ & 76.24 & 6.54 & 75.1 & 6.50 & 77.27 & 6.49 & NS \\
\hline \multirow{2}{*}{ Chin prominence } & Pg-NB mm & 1.21 & 1.24 & 1.17 & 1.32 & 1.24 & 1.17 & NS \\
\hline & $\mathrm{N}^{\circ}$ & 62.06 & 5.05 & 63.11 & 3.96 & 61.09 & 5.77 & NS \\
\hline \multicolumn{9}{|l|}{ Dental variables } \\
\hline \multicolumn{2}{|l|}{$1-\bar{I}^{\circ}$} & 115.89 & 7.39 & 117.67 & 8.34 & 114.25 & 6.038 & $<0.05^{*}$ \\
\hline \multicolumn{2}{|l|}{$1-\mathrm{NA}^{\circ}$} & 27.47 & 5.40 & 27.24 & 6.46 & 27.68 & 4.29 & NS \\
\hline \multicolumn{2}{|l|}{$1-\mathrm{NB}^{\circ}$} & 34.24 & 4.90 & 33.27 & 5.11 & 35.13 & 4.59 & NS \\
\hline \multicolumn{2}{|l|}{ 1-NA mm } & 7.39 & 2.01 & 7.31 & 2.19 & 7.46 & 1.85 & NS \\
\hline \multicolumn{2}{|l|}{ 1-NB mm } & 9.19 & 2.25 & 9.34 & 2.5 & 9.05 & 2.03 & NS \\
\hline \multicolumn{9}{|c|}{ Soft tissue variable } \\
\hline \multicolumn{2}{|l|}{$\mathrm{H}^{\circ}$} & 13.19 & 3.80 & 13.93 & 4.34 & 12.51 & 3.13 & NS \\
\hline
\end{tabular}

NS: not significant **Significant $p<0.01$ level * Significant $p<0.05$ level

Table 3: Comparison of cephalometric norms of Sudanese adults with other population samples

\begin{tabular}{|c|c|c|c|c|c|c|c|}
\hline \multicolumn{2}{|c|}{ Variable } & $\begin{array}{c}\text { Sudanese } \\
\qquad(n=73)\end{array}$ & $\begin{array}{l}\text { Saudi } \\
(n=70)\end{array}$ & $\begin{array}{c}\text { Jordanian } \\
(n=65)\end{array}$ & $\begin{array}{c}\text { Emirati } \\
(n=61)\end{array}$ & $\begin{array}{c}\text { Zimbabwean } \\
(n=50)\end{array}$ & $\begin{array}{c}\text { Nigerians } \\
(n=100)\end{array}$ \\
\hline \multicolumn{8}{|l|}{ Skeletal } \\
\hline \multirow{5}{*}{ Antero-posterior } & SNA $^{\circ}$ & 84.54 & 80.8 & 80.7 & 81.7 & 88.51 & 85.54 \\
\hline & $\mathrm{SNB}^{\circ}$ & 81.51 & 77.5 & 77.7 & 78.6 & 83.3 & 81.22 \\
\hline & $\mathrm{ANB}^{\circ}$ & 3.03 & 3.7 & 3 & 3.1 & 5.3 & 4.33 \\
\hline & $\mathrm{SNPg}^{\circ}$ & 82.22 & - & - & - & - & - \\
\hline & $\mathrm{NSBa}^{\circ}$ & 135.97 & - & - & - & - & - \\
\hline \multirow{4}{*}{$\begin{array}{l}\text { Vertical } \\
\text { inclination }\end{array}$} & ML-NSL ${ }^{\circ}$ & 31.25 & 35.9 & - & 34.6 & - & - \\
\hline & NL-NSL ${ }^{\circ}$ & 8.61 & - & - & 9.55 & - & - \\
\hline & $\mathrm{ML}-\mathrm{NL}^{\circ}$ & 22.82 & - & 25.5 & 25 & 19.88 & - \\
\hline & Gn-tgo-Ar ${ }^{\circ}$ & 117.85 & - & - & - & - & - \\
\hline \multirow{3}{*}{ Face height } & N-Sp' mm & 55.63 & - & - & - & - & - \\
\hline & Sp'-Gn mm & 73.29 & - & - & - & - & - \\
\hline & $\frac{\mathrm{N}-\mathrm{Sp}^{\prime}}{\mathrm{Sp}-\mathrm{Gn}} \times 100$ & 76.24 & - & - & - & - & - \\
\hline \multirow{2}{*}{ Chin prominence } & Pg-NB mm & 1.06 & - & - & - & -0.7 & - \\
\hline & $\mathrm{N}^{\circ}$ & 62.06 & - & - & - & - & - \\
\hline \multicolumn{8}{|l|}{ Dental variables } \\
\hline \multicolumn{2}{|l|}{$I-I^{\circ}$} & 115.89 & 120.6 & 127.5 & 118.6 & 116.5 & - \\
\hline \multicolumn{2}{|l|}{$1-N A^{\circ}$} & 27.47 & 27.3 & - & - & 20.6 & - \\
\hline \multicolumn{2}{|l|}{$1-\mathrm{NB}^{\circ}$} & 34.24 & 29.34 & - & - & 37.6 & - \\
\hline \multicolumn{2}{|l|}{ 1-NA mm } & 7.39 & 6.8 & - & 6.1 & 6.4 & - \\
\hline \multicolumn{2}{|l|}{ 1-NB mm } & 9.19 & 7.5 & - & 6.6 & 10.3 & - \\
\hline \multicolumn{8}{|c|}{ Soft tissue variable } \\
\hline \multicolumn{2}{|l|}{$\mathrm{H}^{\circ}$} & 13.19 & - & - & - & - & - \\
\hline
\end{tabular}


Gender dimorphism was noted in many of the sagittal, vertical and dental parameters which may be explained by the different genetic makeup of the male and female samples. Differences noted between the Sudanese sample and other races may be attributed to the different in racial background. Sudanese sample showed cephalometric values that lied between the Arabs and the Africans which demonstrate clearly the Afro-arabian mixture of Sudanese.

Sudanese females tended to have greater bimaxillary proclination of the incisors than the males $(p<0.05)$ indicated by the lesser interincisal angle. This finding is similar to the result obtained for the Kuwaitis." "The present finding revealed that the Sudanese had increased bimaxillary proclination when compared to the Arabs, ${ }^{11-17}$ similar to Zimbabweans ${ }^{23}$ but lesser than Nigerians ${ }^{20}$ and Kenyans. ${ }^{22}$ This may again reflect the Afro-arabian mixture of the Sudanese population.
Further studies are recommended among different age and ethnic groups among the Sudanese population to provide overall view of the normal occlusion.

\section{CONCLUSION}

- Sudanese adults possess distinct cephalometric norms which should be used in treating Sudanese orthodontic patients.

- Sudanese males showed more maxillary, mandibular, and chin prognathism than females.

- Sudanese females showed more posterior inclination of the maxilla and the mandible but with shorter facial height compare to male samples.

\section{REFERENCES}

1. Moyer RE. Handbook of Orthodontics. 4th ed, Michigan, Mosby, 1988.

2. Broadbent BH. A new x-ray technique and its application to orthodontic practice. Angle Orthod 1931; 1:45-66.

3. Munandar S, Snow MD. Cephalometric analysis of Deutero-Malay Indonesians. Aus Dent J 1995; 40(6):381-8.

4. Bishara SE, Abdalla EM, Hoppens BJ. Cephalometric comparisons of dentofacial parameters between Egyptian and North American adolescents. Am J Orthod 1990; 97(5):413-21.

5. Downs WB. Analysis of the dentofacial profile. Am J Orthod 1956; (4):191-212.

6. Steiner CC. Cephalometrics for you and me. Am J Orthod 1953; 39:729-55.

7. Hasund A. Clinical cephalometry for the Bergen-technique, University of Bergen, Norway, 1977.

8. McNamara JA. A method of cephalometric analysis. Am J Orthod 1984; (12):449-69.

9. Rakosi T. An atlas and manual of cephalometric radiography. Philadelphia, Pennsylvania, Lea \& Febiger, 1982.

10. Shalhoub SY, Sarhan OA, Shaikh HS. Adult cephalometric norms for Saudi Arabians with a comparison of values for Saudi and North American Caucasians. Br J Orthod 1987; 14:273- 9.

11. Behbehania F, Hicks EP, Beeman C, Klvemper GT, Rayens MK. Racial variations in cephalometric analysis between Whites and Kuwaitis. Angle Orthod 2006; 76:406-11.

12. Hassan AH. Cephalometric norms for the Saudi adults living in the western region of Saudi Arabia. Angle Orthod 2006; 76(1):109-13.

13. Hashim HA, AlBarakati SF. Cephalometric soft tissue profile analysis between two different eethnic groups: A comparative study. J Contemp Dent Pract 2003; 4(2):60-73.

14. Hammdan AM, Rock WP. Cephalometric norms in Arabians. J Orthod 2001; 28(4): 297-300.

15. Al Zain T, Ferguson DJ. Cephalometric characterization of an adult Emirati sample with Class I malocclusion. J Orthod Sci 2012 ; 1:1 1-5.

16. Abu-Tayyem, H, Alshams Ai, Hafez S, EIDin E. Cephalometric norms for a sample of Emirates adults. Open J Stomatology 2011 ; 1:75-83.

17. Aboul-Azm SF, Fahmy MA. Soft tissue analysis of the face in Egyptian young adults. Alex Dent J 1980; 5:85-92

18. Kowalski CJ, Harris JE, Walker SJ. The craniofacial morphology of Nubian school children. Angle Orthod 1975; 45(3):180-4.

19. Isiekwe M. A cephalometric study of incisor angulations in a Nigerian population. Br J Orthod 1989; 16:177-81.

20. Utomil IL. A cephalometric study of antero-posterior skeletal jaw relationship in Nigerian Hausa-Fulani children. West Afr J Med 2004; 23(2):119-22.

21. Ajayi EO. Cephalometric norms Nigerian children. Am J Orthod Dentofac Orthop 2005; 128(5):653-6.

22. Kapila S. Selected cephalometric angular norms in Kikuyu children. Angle Orthod 1989; 59(2):139-44.

23. Dandajena TC, Nanda RS. Bialveolar protrusion in a Zimbabwean sample. Am J Orthod Dentofac Orthod 2003; 123(2):133-7.

24. Miyajima K, MCNamara J, Kimura T, Murata S, lizuka T. Craniofacial structure of Japanese and European-American adults with normal occlusions and well-balanced faces. Am J Orthod 1996; 110(4):431-8.

25. Engel G, Spolter BM. Cephalometric and visual norms for a Japanese population. Am J Orthod 1981; 80:48-60.

26. Alcalde RE, Jinno T, Pogrel A, Matsumura T. Cephalometric norms in Japanese adults. J Oral Maxillofac Surg 1998; 56:129-I34.

27. Houston WJB. The analysis of errors in orthodontic measurements. Am J Orthod 1983; 83(5):382-90.

28. Athanasiou AE. Orthodontic cephalometry. London, Mosby, St Louis, International; 1995. 